\title{
PENGARUH PEMBELAJARAN INKUIRI TERBIMBING TERHADAP PEMAHAMAN KONSEP FISIKA PESERTA DIDIK
}

\author{
Muhmmad Amran Shidik ${ }^{1}$ Faradina $^{2}$ Pertiwi $^{3}$ Anas Irwan ${ }^{4}$ \\ ${ }^{1}$ Universitas Timor \\ ${ }^{2}$ STKIP KIE Raha \\ ${ }^{3}$ Universitas Pancasakti \\ ${ }^{4}$ Universitas Islam Negeri Alauddin \\ e-mail: muh.amranshidik@gmail.com
}

\begin{abstract}
The Effect Of Guided Inquiry Learning On Student's Understanding Of Physics Concepts. This research was conducted with the aim of knowing the effect of guided inquiry learning on students' understanding of physics concepts. This study used a quasi-experimental research method with a non-equivalent control group design. The number of samples in the study were 64 students. Data collection was carried out by providing an objective test of concept understanding in the form of a multiplechoice test of 15 questions with five answer choices. The data obtained are then tested for prerequisites first. After the data is said to be normally distributed and homogeneous, it is continued with hypothesis testing using t-test. The results of the $t$-test indicate that the significance value is smaller than the value of $(0.000<0.05)$, so Ho is rejected, and $\mathrm{Ha}$ is accepted. This means that there is an influence on understanding the concept of physics between participants being taught to learn guided inquiry and being taught conventionally.
\end{abstract}

Keywords: Learning, Guided Inquiry, Concept Understanding, Physics

\begin{abstract}
Abstrak: Pengaruh Pembelajaran Inkuiri Terbimbing Terhadap Pemahaman Konsep Fisika Peserta Didik. Penelitian ini dilakukan dengan tujuan untuk mengetahui pengaruh pembelajaran inkuiri terbimbing terhadap pemahaman konsep fisika peserta didik. Penelitian ini menggunakan metode penelitian eksperimen semu dengan desain penelitian Non-Equivalent Control Grup Design. Jumlah sampel dalam penelitian adalah 64 orang peserta didik. Pengumpulan data dilakukan dengan memberikan tes objektif pemahaman konsep berupa tes pilihan ganda sejumlah 15 soal dengan lima pilihan jawaban. Data yang diperoleh kemudian diuji prasyarat terlebih dahulu. Setelah data dikatakan berdistribusi normal dan homogen dilanjutkan dengan pengujian hipotesis menggunakan uji-t. Hasil uji t menunjukkan bahwa nilai signifikansi lebih kecil dari nilai $\alpha(0,000<0,05)$, sehingga Ho ditolak dan Ha diterima. Artinya ada pengaruh pemahaman konsep fisika antara peserta diajar belajar inkuiri terbimbing dan diajar secara konvensional.
\end{abstract}

Kata kunci: Pembelajaran, Inkuiri Terbimbing, Pemahaman Konsep, Fisika 


\section{PENDAHULUAN}

Pendidikan sebagai kebutuhan yang mendasar dan penting bagi setiap manusia (Marpaung, 2020). Pendidikan adalah suatu kegiatan yang terjadi di setiap kehidupan setiap manusia sebagai usaha untuk menyeimbangkan keadaan dalam diri dengan luar diri sendiri. Dengan adanya pendidikan diharapkan terbentuknya individu-individu yang terdidik dan mampu membangun kehidupan menjadi lebih baik. Pembelajaran adalah usaha dari guru untuk mengarahkan peserta didiknya pada proses belajar dan mengarahkan peserta didiknya untuk berinteraksi dengan sumber belajar lainnya (Trianto, 2007). Dalam proses pembelajaran, peserta didik harus menguasi konsep materi yang dipelajari (Batlolona et al., 2018). Keberhasilan peserta didik dalam menguasai konsep bukan tentang bagaimana menjawab dengan benar dan sistematis tetapi bagaimana peserta didik memahami proses fisik dari masalah yang ada (Wambugu \& Changeiywo, 2008). Oleh karena itu, pemahaman konsep yang lengkap sangat diperlukan.

Dari hasil observasi awal peneliti,dengan melakukan wawancara terhadap guru fisika pada kelas X MIA, mengatakan jika peserta didiknya masih sangat kurang untuk memahami konsep fisika yang diajarkan terutama pada kelas $\mathrm{X}$ MIA. Selain itu peneliti mewawancarai peserta didik pada kelas $\mathrm{X}$ dan melalui wawancara ini, diperoleh bahwa peserta didik secara umum menganggap bahwa fisika sebagai pelajaran yang sulit karena dalam kegiatan belajar di dalam kelas terkadang peserta didik kurang paham dengan penjelasan dari guru sehingga mereka menjadi kurang tertarik dengan pelajaran fisika.

Berdasarkan uraian sebelumnya, ada beberapa hal tertentu yang mestinya dibenahi ketika pembelajaran di kelas berjalan, untuk membuat peserta didik paham dengan penyampain materi dari guru serta mereka bukan saja berlaku sebagai pendengar saja tetapi harus aktif dalam pembelajaran. Memahami sebuah konsep ketika pembelajaran adalah hal yang paling penting, sebab ketika pembelajaran fisika untuk mengaplikasikan suatu konsep tentunya harus dengan memahi konsep terlebih dahulu.
Pemahaman merupakan kemampuan berpikir manusia yang menjadi dorongan disetiap satuan pendidikan dan universitas (Shidik, 2020).

Dalam sebuah penelitian yang dilakukan oleh (Hartanto, 2017), disimpulkan jika ada banyak peserta didik yang memiliki miskonsepsi hal ini desebabkan oleh masih banyak dari mereka yang belum paham dengan konsepkonsep fisika yang diajarkan. Penelitian lainnya yang dilakukan oleh (Elisa et al., 2017), ditemukan bahwa masih ada beberapa mahasiswa yang kurang paham dengan teoriteori fisika pada, hal ini diketahui melalui uji coba pengerjaan soal mengenai materi tersebut yang hasinya sebagi dari mahasiswa hanya mampu menjawab soal perhitungan sederhana saja sedangkan untuk perhitungan tingkat lanjut mahasiswa masih bingung disebabkan harus memahi konsep dengan baik terlebih dahulu.

Uraian di atas mengungkapkan pentingnya peserta didik agar memahami konsep dengan baik untuk memudahkan mereka dalam kegiatan belajar. Maka, diperlukan sebuah pembelajaran yang mampu membuat peserta didik memahi konsep-konsep pada suatu materi khususnya materi-materi fisika. Salah satu pembelajaran yang baik digunakan agar mudah memahami konsep adalah Pembelajaran Inkuiri Terbimbing.

Menurut (Anam, 2015) guided inquiry learning merupakan pembelajaran dimana pelaksanaannya guru sebagai penyedia dan pemberi arahan yang tepat kepada peserta didik..dengan memberikan..suatu masalah agar dibuatkan pemecahan masalahnya oleh peserta didik dengan bimbingan dari guru. Dari definisi, terlihat bahwa dengan menggunakan pembelajaran di atas diharapkan peserta didik dapat ikut serta aktif dalam pembelajaran sehingga memungkinkan untuk mereka mudah ketika memahami konsep yang. Disampaikan oleh guru.

Dalam penelitian (Dewi \& Sudana, 2016) serta (Setyawati \& Candiasa, Yudana, 2014), diperoleh bahwa.inkuiri terbimbing berpengaruh.baik pada pemahaman konsep peserta didik. Beberapa tahap pembelajaran inkuiri terbimbing menurut (Trianto, 2007) adalah "menyajikan masalah, merumuskan hipotesis, mengumpulkan data, menguji hipotesis, dan merumuskan kesimpulan". 
Berdasarkan situasi yang telah diuraikan sebelumnya, maka peneliti mengangkat tema penelitian yaitu Pengaruh Pembelajaran Inkuiri Terbimbing Terhadap Pemahaman Konsep Fisika Peserta Didik.

\section{METODE}

Eksperimen semu digunakan dalam penelitian ini, Desian penelitian adalah NonEquivalent Control Grup Design yang merupakan bagian dari eksperimen semu. Dengan membagi dua kelompok yakni kelompok eksperimen dengan perlakuan pembelajaran inkuiri terbimbing dan kontrol yang tidak diberi perlakuan.

Penelitian ini dilakukan di MAN Baraka Kab. Enrekang Sulawesi Selatan. Populasi penelitian adalah semua peserta didik pada $X$ MIA yang totalnya 121 peserta didik yang tersebar kedalam 4 kelas. Purposive sampling digunakan untuk menarik sampel, artinya sampel dipilih langsung oleh peneliti dengan mempertimbangkan keadaan tertentu, sehingga didapatkan dua kelas yaitu X MIA 3 (kelompok kontrol) dan X MIA 4 (kelompok eksperimen). Yang menjadi pertimbangan kelas MIA 3 dan 4 diambil adalah seluruh kelas dalam pembagiannya tidak dibeda-bedakan berdasarkan prestasi atau diacak dalam penempatan kelas oleh pihak sekolah. Selain itu, berdasarkan instruksi dari kepala sekolah bahwa untuk sementara hanya kelas MIA 3 dan 4 yang dapat digunakan untuk penelitian. Jumlah sampel dari kedua kelas ini diperoleh 64 peserta didik masing 32 peserta didik pada kelas MIA 3 dan 32 peserta didik pada kelas MIA 4.

Data penelitian diperoleh melalui tes pemahaman konsep yang diberikan setelah peserta didik mendapat perlakuan pembelajaran inkuiri terbimbing. Materi yang yang digunakan dalam dalam Menyusun instrument tes adalah materi momentum, impuls dan tumbukan. Insturmen tes yang digunakan merupakan tes pilihan ganda dengan lima opsi jawaban. Dengan jumlah butir soal sebanyak 15 butir. Instrumen tes telah diuji reliabilitasnya dan diperoleh koefisien reliabilitas sebesar 0,862 , yang berarti instrument dapat dikatakan reliabel sebab koefisien reliabilitas lebih besar dari 0,70 (Yusup, 2018).

Setelah data dikumpulkan, peneliti melakukan uji analisis deskriptif dan analisis inferensial (uji t) untuk melihat ada pengaruh (Jainuddin et al., 2020; Yusnarti \& Suryaningsih, 2021) pembelajaran inkuiri terbimbing pada pemahaman konsep peserta didik. Sebelum melakukan analisis inferensial, peneliti melaksanakan uji prasyarat melalui uji normalitas dan homogenitas agar mengatahui apakah sudah tepat memakai uji-t atau menggunakan uji yang lainnya.

\section{HASIL DAN PEMBAHASAN}

Analisis deskriptif dari data diperoleh sesuai dengan tabel 1 di bawah:

Tabel 1. Statistik Deskriptif Pemahaman Konsep Fisika

\begin{tabular}{|c|c|}
\hline \multicolumn{2}{|c|}{ K. Eksp } \\
\hline Skor Ideal & 15 \\
\hline Maks & 11 \\
\hline Min & 2 \\
\hline Rata-rata & 6,53 \\
\hline $\mathrm{SD}$ & 2.14 \\
\hline $\begin{array}{l}\text { Dari tabel, diketahui bahwa skor } \\
\text { maksimal pemahaman konsep fisika untuk } \\
\text { kelompok kontrol lebih. tinggi yaitu } 11 \\
\text { dibandingkan dengan skor pada kelompok } \\
\text { eksperimen yakitu 10. Namun jika dilihat rata- } \\
\text { rata skor secara berkelompok, yang lebih unggul }\end{array}$ & $\begin{array}{l}\text { adalah kelompok. eksperimen dari kelompok } \\
\text { control }(7>6,53) \text {. } \\
\text { Sesudah analisis deskriptif, peneliti lalu } \\
\text { mengerjakan analisis inferensial menggunakan } \\
\text { uji t-test. Namun sebelumnya, peneliti } \\
\text { melakukan uji prasayarat data. Uji prasyarat } \\
\text { dapat dilihat hasilnya pada tabel } 2 \text { dan tabel } 3 .\end{array}$ \\
\hline
\end{tabular}


Karst : Jurnal Pendidikan Fisika dan Terapannya

Volume 4 | Nomor 2 | 47

p-ISSN: 2622-9641 e-ISSN: 2655-1276

Tabel 2. Hasil Uji Normalitas

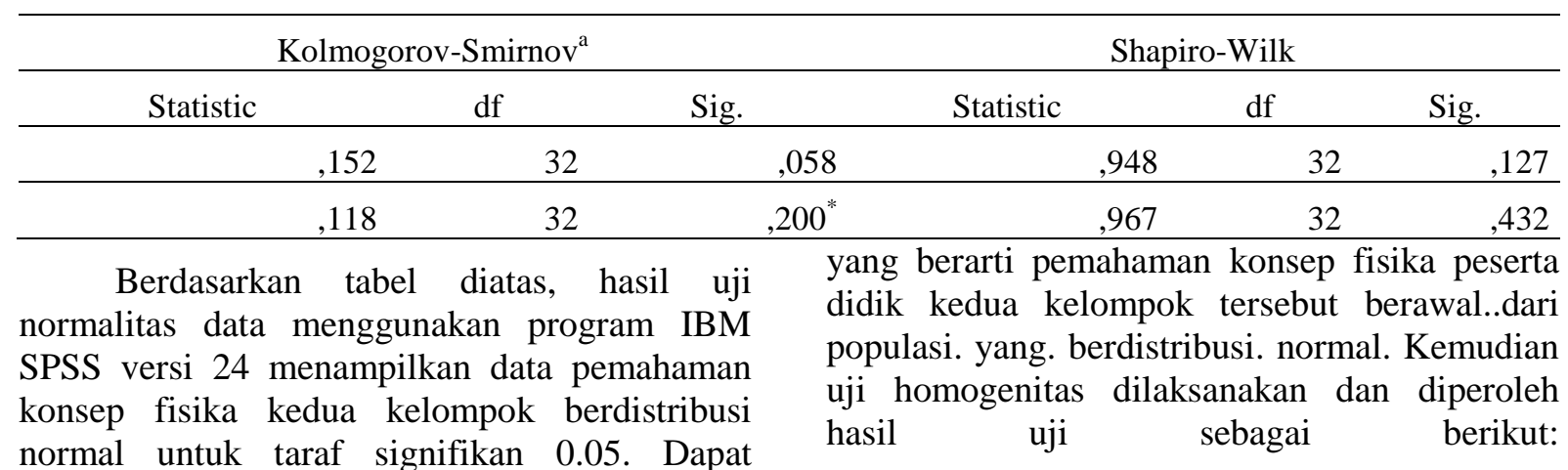

ketahui nilai Sig. pada tabel $2>0.05$ (nilai $\alpha$ )

Tabel 3. Hasil Uji Homogenitas

\begin{tabular}{cccc}
\hline Levene Statistic & df1 & df2 & Sig. \\
\hline 107 & 1 & 62 & 0,745 \\
\hline
\end{tabular}

Dari tabel diatas, menunjukkan bahwa ke dua kelompok berawal dari polulasi yang.homogen dengan.taraf signifikan $\alpha=0,05$. Dapat dilihat dari nilai signifikasi pada kolom sig. yaitu $0,745>0,05$ (nilai $\alpha$ ), artinya data yang diperoleh dari kedua kelompok memliki

kesamaan karakteristik. Oleh karena hasil dari uji prasyarat telah terpenuhi, maka dilanjutkan dengan uji t-test untuk menguji hipotesis yang telah diangkat sebelumnya. Hasil uji t-test dapa dilihat pada tabe berikut:

Tebel 4. Hasil Uji t-test

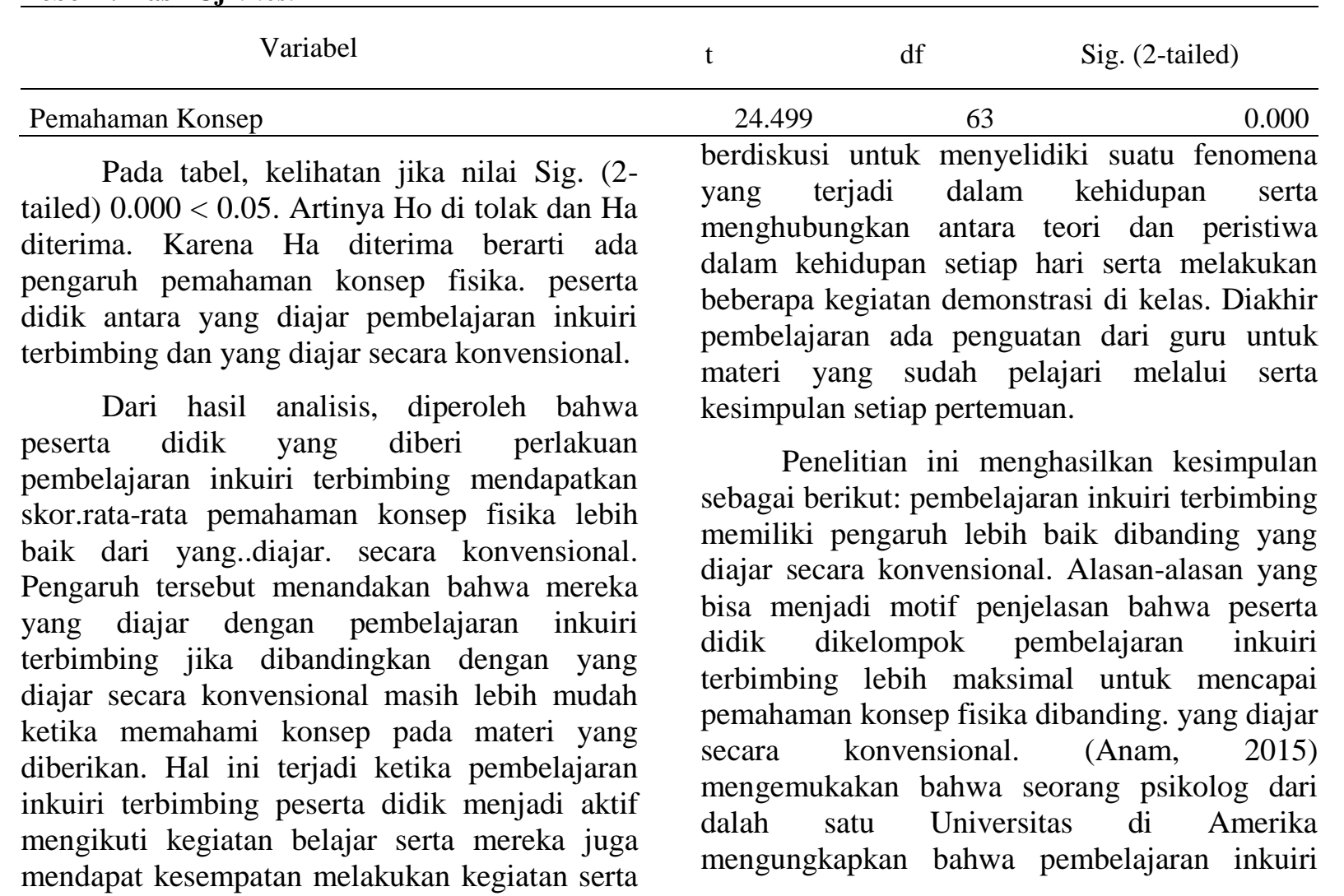


memiliki salah satu kelebihan yaitu peserta didik menjadi lebih gampang memahami beberapa konsep dasar dan ide yang lebih baik.

Guided Inquiry memiliki hubungan yang kuat dengan motivasi dalam pembelajaran terutama motivasi dalam menemukan pemahaman baru. Menurut (Anam, 2015) pembelajaran ini memiliki keistimewaan yang harus diperhatikan, yaitu guru memberi motivasi peserta didik ketika menyampaikan hasil abstraksinya agar bisa difungsikan oleh temantemannya di kelas. Jadi pembelajaran ini adalah salah satu pembelajaran yang meletakkan esesnsinya pada keaktifan peserta didik, menyelaraskan materi dengan pengalaman belajar, menemukan rasa percaya diri dan menumbuhkan kepuasan mereka, sehingga terjadilah proses belajar yang diharapkan.

Jika dibandingkan, peserta didik yang diajar secara konvensional guru lebih didominasi kegiatan belajar selama proses belajar mengajar terjadi serta sangat jarang guru memberikan aplikasi agar memudahkan pemahaman mereka. Ini jelas, menjadikan mereka penerima materi yang tidak aktif dan hanya menerima materi yang diberikan guru tampa mendapat peluang untuk menganalisis sendiri persoalan yang sedang selidiki. Peserta didik pada akhirnya tidak mampu mencerna materi pelajaran yang dipelajarinya ketika belajar dan sulit mengembangkan kemampuan merumuskan masalah sendiri, memberikan contoh, membuat hipotesis dan hal lainnya.

Sejalan dengan penelitian dari (Maladjuna et al., 2017; Sholikhan, 2016; Siahaan et al., 2021; Sulistiyono, 2021) menyimpulkan bahwa terdapat pengaruh pemahama konsep peserta didik antara yang diajar pembelajaran inkuiri terbimbing dan secara konvensional, dimana peserta didik dapat lebih memahami konsep dengan baik. Berdasarkan uaraian di atas, diketahui jika pembelajaran inkuiri terbimbing mampu membantu dan melatih peserta didik dalam pembelajaran terutama saat melatih pemahaman konsep mereka (Puspitasari et al., 2019). Dalam pembelajaran inkuiri terbimbing, seorang guru akan menjadi fasilitator dimana guru hanya bertindak untuk memfasilitasi kegiatan peserta didik (Siahaan et al., 2021) ketika menganalisis dan menyelesaikan masalah.
Ini yang menjadi beberapa faktor kecil yang menjadikan peserta didik dapat memahami konsep dengan.baik dari yang diajar secara konvensional.

\section{PENUTUP}

Hasil penelitan menyimpulkan bahwa ada pengaruh pemahaman konsep fisika peserta didik antara yang diajar pembelajaran inkuiri terbimbing dan yang diajar secara konvensional. Dimana pengaruh yang diberikan oleh pembelajaran inkuiri terbimbing adalah pengaruh positif.

\section{DAFTAR PUSTAKA}

Anam, K. (2015). Pembelajaran Inkuiri Metode dan Aplikasi. Pustaka Pelajar.

Batlolona, J. R., Baskar, C., Kurnaz, M. A., \& Leasa, M. (2018). The Improvement of ProblemSolving Skills and Physics Concept Mastery on Temperature and Heat Topic. Jurnal Pendidikan IPA Indonesia, 7(3), 273-279. https://doi.org/10.15294/jpii.v7i3.12432

Dewi, N. L. Gd. K. K., \& Sudana, Dw. Nym. (2016). Pengaruh Model Pembelajaran Inkuiri Terbimbing Terhadap Pemahaman Konsep Ipa Dengan Mengontrol Minat Belajar Pada Siswa Kelas V Sd. Jurnal Pendidikan Dan Pengajaran, $49(1), \quad 40$. https://doi.org/10.23887/jppundiksha.v49i1. 9008

Elisa, E., Mardiyah, A., \& Ariaji, R. (2017). PENINGKATAN Pemahaman Konsep Fisika Dan Aktivitas Mahasiswa Melalui PhET SIMULATION. PeTeKa, l(1), 15. https://doi.org/10.31604/ptk.v1i1.15-20

Hartanto, T. J. (2017). Studi Tentang Pemahaman Konsep-konsep Fisika Sekolah Menengah Pertama di Kota Palangka Raya. Risalah Fisika, l(1), 9-14. https://doi.org/10.35895/rf.v1i1.14

Jainuddin, J., S, S. S., \& Sirajuddin, S. (2020). Pengaruh Minat dan Kedisiplinan Siswa dengan Gaya Kognitif Field Indefendent terhadap Hasil Belajar Matematika Siswa SMK Farmasi Yamasi Makassar. Delta-Pi: Jurnal Matematika dan Pendidikan 
Karst : Jurnal Pendidikan Fisika dan Terapannya Volume 4 | Nomor 2 | 49 p-ISSN: 2622-9641 e-ISSN: 2655-1276

Matematika, 9(2), Article https://doi.org/10.33387/dpi.v9i2.2283

Maladjuna, D. A., Saehana, S., \& Syamsu, S. (2017). Pengaruh Model Pembelajaran Inkuiri Terbimbing Terhadap Pemahaman Konsep Siswa pada Mata Pelajaran Fisika di SMP Negeri 19 Palu. JPFT (Jurnal Pendidikan Fisika Tadulako Online), 5(1), 7. https://doi.org/10.22487/j25805924.2017.v5. i1.7126

Marpaung, J. V. (2020). Penerapan Konsep Pembelajaran Industri 4.0 pada Pendidikan Dasar Desain. Jurnal Desain Idea: Jurnal Desain Produk Industri Institut Teknologi Sepuluh Nopember Surabaya, 19(1), 19-26. https://doi.org/10.12962/iptek_desain.v19i1. 7011

Puspitasari, R. D., Mustaji, M., \& Rusmawati, R. D. (2019). Model Pembelajaran Inkuiri Terbimbing Berpengaruh terhadap Pemahaman dan Penemuan Konsep dalam Pembelajaran PPKn. Jurnal Imiah Pendidikan dan Pembelajaran, 3(1), 96107. https://doi.org/10.23887/jipp.v3i1.17536

Setyawati, N. W. I., \& Candiasa, Yudana, I. M. (2014). Pengaruh Model Pembelajaran Inkuiri Terbimbing Terhadap Pemahaman Konsep Dan Keterampilan Proses Sains Siswa Kelas XI IPA SMA Negeri 2 Kuta Kabupaten Badung. Jurnal Administrasi Pendidikan UNDIKSHA, 5(1).

Shidik, M. A. (2020). Pengaruh Konsep Diri dan Motivasi Berprestasi Terhadap Hasil Belajar Fisika Peserta Didik. Andragogi: Jurnal Diklat Teknis Pendidikan Dan Keagamaan, $8(2)$, 553-569. https://doi.org/10.36052/ANDRAGOGI.V8I 2.177
Sholikhan. (2016). Understanding Concepts Through Inquiry Learning Strategy. . IOSR Journal of Research \& Method in Education (IOSRJRME), 7(1).

Siahaan, K. W. A., Lumbangaol, S. T. P., Marbun, J., Nainggolan, A. D., Ritonga, J. M., \& Barus, D. P. (2021). Pengaruh Model Pembelajaran Inkuiri Terbimbing dengan Multi Representasi terhadap Keterampilan Proses Sains dan Penguasaan Konsep IPA. Jurnal Basicedu, 5(1), 195-205. https://doi.org/10.31004/basicedu.v5i1.614

Sulistiyono, S. (2021). Efektivitas Model Pembelajaran Inkuiri Terbimbing Terhadap Keterampilan Proses Sains Dan Pemahaman Konsep Fisika Siswa MA Riyadhus Solihin. Jurnal Pendidikan Fisika Undiksha, 10(2), 61-73.

https://doi.org/10.23887/jjpf.v10i2.27826

Trianto. (2007). Mendesain Model Pembelajaran Inovatif-Progresif. Kencana Prenada Media Group.

Wambugu, P. W., \& Changeiywo, J. M. (2008). Effects of Mastery Learning Approach on Secondary School Students' Physics Achievement. Eurasia Journal of Mathematics, Science and Technology Education, 4(3), 293-302. https://doi.org/10.12973/ejmste/75352

Yusnarti, M., \& Suryaningsih, L. (2021). Pengaruh Model Pembelajaran Role Playing Terhadap Hasil Belajar Siswa Sekolah Dasar. Ainara Journal (Jurnal Penelitian Dan PKM Bidang Ilmu Pendidikan), 2(3), 253-261. https://doi.org/10.54371/ainj.v2i3.89

Yusup, F. (2018). Uji Validitas dan Reliabilitas Instrumen Penelitian Kuantitatif. Tarbiyah: Jurnal Ilmiah Kependidikan, 7(1), Article 1. https://doi.org/10.18592/tarbiyah.v7i1.2100 